\title{
Preventing Iron Deficiency in the Hmong Community
}

\author{
Becky Damazo and Jane Moua \\ California State University, Chico, School of Nursing
}

\begin{abstract}
There is a high prevalence rate of iron deficiency in Hmong children in the USA. An iron deficiency prevention brochure was developed for the Hmong community to educate parents about the subject. The brochure was developed as a result of a Hmong nursing student working closely with a California State University, Chico, faculty member and the county health department.
\end{abstract}

(C) 2003 Californian Journal of Health Promotion. All contents copyrighted. All rights reserved. Keywords: iron deficiency, Hmong, culturally appropriate, nursing

Iron deficiency is a leading cause of infant morbidity and mortality worldwide (Zlotkin, 2003) According to the World Health Organization, iron deficiency is the most common nutritional disorder in the world. Two billion people - over $30 \%$ of the world's population - are anemic, mainly due to iron deficiency. (WHO, 2003) The overwhelming cause of iron deficiency is dietary in origin. (Harris, 2002).

Toddlers, especially 9 to 18 month olds, are at high risk for iron deficiency. According to the third national Health and Nutrition Examination Survey (NHANES III), 9 percent of toddlers aged one to two years are iron deficient (Brown, 2002) Young children are at great risk of iron deficiency because of rapid growth and increased iron requirements. Iron deficiency, has negative effects on work capacity and on motor and mental development in infants, children, and adolescents, and maternal iron deficiency anemia might cause low birth weight and preterm delivery.

Although iron deficiency is more common in developing countries, a significant prevalence was observed in the United States during the early 1990s among certain populations, such as toddlers and females of childbearing age. One of the national health objectives for 2010 is to reduce iron deficiency in these vulnerable populations by three to four percentage points (Objective No. 19-12) (MMWR, 2002).

Iron deficiency can occur due to a lack of iron in the diet. If this deficiency continues, anemia results. Anemia is a manifestation of iron deficiency when it is relatively severe. Children may be anemic for many reasons but it is usually caused by not getting enough iron from the foods they eat. Iron deficiency anemia is a condition that is preventable. Iron deficiency anemia tends to disproportionately affect minority children.

Hmong children have especially high rates of iron deficiency anemia. According to Paula Henry, an epidemiologist at the St. Paul Department of Public Health, approximately one out of every four Hmong children have anemia (Hmong Tribune, 1999). There are several social and cultural explanations for the feeding practices of Hmong parents that result in excessive milk and inadequate food intake among infants and toddlers contributing to irondeficiency anemia.

A study was conducted to determine if culturally influenced feeding practices were associated with iron deficiency in infants and toddlers from low-income families. A dietary survey, illness history, hematocrit and zinc protoporphyrin-tohemeration $(\mathrm{ZPP} / \mathrm{H})$ from 35 Southeast Asian children and 73 children of other ethnicities 
between ages 5 and 30 months were obtained. The results showed that toddler feeding practices were different between Southeast Asians and other ethnic groups.

Persistence of bottle-feeding after 2 years was common. Southeast Asian parenting practices generally put an emphasis on accommodating infants. Because of this, weaning may be delayed, putting these children at risk for iron deficiency anemia (Zlotkin, 2003). Another factor that contributes to the high rate of anemia in the Hmong population is the fact that families often live in crowded households and place a priority on keeping infants and toddlers from crying or disturbing others. Children are given a bottle when they cry. Toddlers may consume large amounts of milk from a bottle or cup during the night while parents attempt to quiet them (Graham, Carlson, Sodergren, Detter, \& Labbe, 1997).

Infancy is the critical period for brain growth, and nutrient deficiencies during this time may affect psychomotor development and neurocognition. Some of the consequences for iron deficiency include: altered behavior and cognition, altered motor development, Children and adolescents who were anemic as infants can exhibit long term consequences, such as lowered test scores and the need to repeat grades or utilize special services (Zlotkin, 2003).

Language differences between health providers and consumers create a central barrier to the delivery of information about nutrition and iron deficiency (Bull, Holt, Kreuter, Clark, 2001). Without appropriate materials in Hmong and other languages it is extremely difficult to provide information to individuals and families at risk. An extensive library and internet search revealed that there were no readily available brochures on Iron deficiency anemia for Hmong families. Because of this a culturally relevant brochure was developed to distribute in the Hmong community (PDF 3.5MB).

The brochure resulted from the work of a Hmong nursing student, a county health department Hmong translator/ interpreter and California State University, Chico, School of Nursing faculty. The brochure explains briefly what is iron deficiency, signs and symptoms of anemia, children who are at risk, complications if the anemia is untreated, and prevention measures. Language appropriate brochures can be an effective way to communicate information and bring about behavioral changes (Tran, 2002).

When searching for information on iron deficiency, several websites that do contain important health information in a number of languages, including Hmong, were discovered. Table 1 includes links to some wonderful websites that contain brochures and information in Hmong on a number of additional health topics.

Table 1

Links to Online Hmong Resources

\begin{tabular}{|l|l|}
\hline \multicolumn{1}{|c|}{ Hmong Resource } & \multicolumn{1}{c|}{ Web Address } \\
\hline $\begin{array}{l}\text { Health Education Brochures in Multiple } \\
\text { Languages. } \\
\text { Spencer S. Eccles Health Sciences Library, } \\
\text { University of Utah Health Sciences Center }\end{array}$ & http://medstat.med.utah.edu/library/refdesk/24lang.html\#hmong \\
\hline $\begin{array}{l}\text { Hmong Handouts. } \\
\text { Nutrition Education for New Americans } \\
\text { Project, Georgia State University }\end{array}$ & http://multiculturalhealth.org/index/Handouts/Hmong/ \\
\hline Hmong Health. & $\underline{\text { http://www.hmonghealth.org/ }}$ \\
\hline $\begin{array}{l}\text { Translated Education Materials. } \\
\text { Minnesota Department of Health. }\end{array}$ & $\underline{\text { http///www.health.state.mn.us/divs/idepc/diseases/tb/translations.html }}$ \\
\hline
\end{tabular}


Nursing student outreach programs can be a force of influence and inspiration. The community at-large can benefit from student projects that result from careful community assessment and planning. When given the opportunity, students will lend their unique talents to assess and develop tools that benefit their community in a meaningful way.

\section{References}

Brown, J. (2002). Toddler and preschooler nutrition. Nutrition throughout the life cycle. Belmont: Wadsworth, pp. 252-3.

Bull, F. C., Holt, C. L., Kreuter, M. W., Clark, E. M. (2001). Understanding the effects of printed health education materials: Which features lead to which outcomes? Journal of Health Communication, 6, 265-279.

Graham, E. A., Carlson, T. H., Sodergren, K. K., Detter, J. C., \& Labbe, R. F. (1997). Delayed bottleweaning and iron deficiency in Southeast Asian toddlers. The Western Journal of Medicine, 167(1), 10-15.

Harris, R. J. (2002). Is milk best for infants and toddlers? Journal of Nutritional \& Environmental Medicine, 12(3), 145-151.

Hmong Tribune. (1999). Too much cow's milk causes poor nutrition among Hmong children. Retrieved November 26, 2003, from http://members.aol.com/hmongpaper/june99.htm

Tran, A. (2002). Development of targeted message concepts for recent asian immigrants about secondhand smoke. Journal of Health Communication; 7(1), p25, 13p

World Health Organization. (2003). Battling iron deficiency anemia: The challenge. Retrieved November 26, 2003, from http://www.who.int/nut/ida.htm

Zlotkin, S. (2003). Clinical nutrition: 8. The role of nutrition in the prevention of iron deficiency anemia in infants, children and adolescent. Canadian Medical Association Journal, 168(1), 59-64.

\section{Acknowledgements}

The authors would like to thank Long Xiong from the Yuba County, California Department of Health Services, for his editorial assistance and help with the brochure development.

Author Information

Becky Damazo, RN, PNP, MS*

Professor

School of Nursing

California State University, Chico

Chico, CA 95929-0200

E-Mail: bdamazo@csuchico.edu

Jane Moua, RN, BS

School of Nursing

California State University, Chico

* corresponding author 